\title{
Exploring the Motivation of Livestreamed Users in Learning Computer Programming and Coding
}

\author{
Hong Huang ${ }^{1}$ and Yongji $\mathrm{Li}^{2}$ \\ ${ }^{1}$ Associate Professor, School of Information, University of South Florida, USA \\ ${ }^{2}$ Senior Information Architect, Asialnfo Tech, China, P.R. \\ honghuang@usf.edu \\ dragonlyi@gmail.com
}

\begin{abstract}
This article discusses the emerging presence of online livestreaming programs for computer coding education. The typologies of motivations from a user-gratification perspective were explored from live coding streaming platforms such as "Twitch.tv" and "LiveEdu.tv". Categories of motivations were identified from the literature. Content analysis was used for analyzing the distribution of motivation categories in "Twitch.tv," as well as blog posts on "LiveEdu.tv" guided by Gratifications Theory. From the literature, five types of motivations were identified: 1) Cognitive; 2) Affective; 3) Social Integration; 4) Personal Integration; and 5) Tension release. In live coding streaming communities, the content analysis of 256 streams and twenty six discussion posts indicated that the primary motivation is cognitive related information seeking, followed by social integration such as community outreach, and then personal integration such as personal recognition. Through content analysis, the authors found that the audience's psychological state while watching online livestreaming of coding practice is mainly focused on learning and information seeking, emotional connectedness, and social interactions. Based on the findings, an empirical motivation model in live coding streaming was also developed. The findings for researchers and practitioners alike in programming education can apply respective motivation characteristics in programming education.
\end{abstract}

Keywords: Live coding, computational thinking, game-based learning, computer science education, online communities, streaming

\section{Introduction}

With the development of internet technology and the popularization of smart phones, online livestreaming has emerged as a fast-growing method for online media broadcasting in real time. Nearly half of internet users in the US watch live videos at least once a week, and a quarter of them watch live videos at least once a day (Kats, R. 2017). The scale of the video streaming market was estimated at approximately $\$ 30$ billion in 2016, and it is projected to more than double in growth by 2021, to more than $\$ 70$ billion (PR Newswire, 2016).

Over $60 \%$ of young people (ages 18-34) watch livestreaming content regularly in the U.S. (Emarketer, 2017). As an example, Twitch is one of the biggest live video streaming companies, with about 1 million streamers interacting with more than 100 million viewers each month (Twitch, 2017). Another big livestreaming platform, "Facebook Live," attracts nearly two billion people to watch live videos, with an increase of 50\% in 2017 (Fingas, 2018). In China, which has the largest live video streaming market, with 324.8 million Internet users (or $45 \%$ of its online users) making use of livestreaming content, more than 200 live video streaming apps are available (Chadha, 2016; Si, 2017; Xiang, 2017). Most of these live video streaming programs are related to video games, live shows, and e-sports.

Livestreaming meets the social requirements of people at different levels, including face-to-face, anywhere, anytime, and interactive. Live video streaming allows people to watch videos on different platforms through the network system at the same time. The emergence of livestreaming platforms has triggered a revolution in communication. Online video livestreaming can be used to produce videos and their related dialogues, metadata, online survey, program evaluations, and other online training materials (Derry et al., 2010).

Livestreaming, however, has a much broader scope than just entertainment and gaming; livestreaming has also emerged in other genres. In recent years, the demand for adding programming and computational thinking into primary school curricula has increased greatly (Repenning, Webb and loannidou, 2010); this gives incentive to consider novel approaches such as livestreaming, which have been shown to be used to disseminate programming and coding knowledge. Interestingly, new livestreaming platforms such as "Twitch.tv" and "LiveEdu.tv" (now named: "education-ecosystem") lead a new way on this. "Twitch.tv" is a popular livestreaming platform primarily for entertainment and sports, but also includes streaming for livestream computer programming. "LiveEdu.tv" primarily focuses on computer programming education, which engages a good 
numbers of programming experts as streamers and viewers in a rapidly growing livestreaming multimedia phenomenon.

Live coding benefits programmers by allowing for easy debugging and immediate feedback during the coding process (McDirmid, 2016; Kubelka, 2018); however, little is known about the user motivations underlying streamer and viewer engagement towards using livestreaming for effective and enjoyable coding learning. Unlike other live streaming activities, such as gaming or sports, primarily for recreation purposes, live streamers and participants for coding learning benefit from personal learning experiences and hands-on problem-solving skills. Live coding streaming promotes informal coding education in a variety of ways. Motivational experimentation in a live-stream coding environment sheds light on the growing needs of live streaming-focused programming. Unknown motivations, specifically learning related motivations, can be defined to apply live streaming and re-use different interaction features to deliver a better online learning strategy.

In this research, the empirical motivation model in live-stream coding is built based on the Uses and Satisfaction Theory (Rubin, 2009), with supporting evidence derived from content analysis among live streaming coding platforms. Motivation discovery and modeling articulate the needs of streamer-viewer interaction, which helps to develop motivation-specific learning resources to facilitate information sharing, adaptive data workflow, and cognitive participatory learning environment.

\section{Literature Review}

Livestreaming demonstrates tremendous user benefits and the potential to grow into an even broader social media trend (Hilvert-Bruce et al., 2018). Uses and Gratification Theory (UGT) has been used to analyze how people engage in different types of social media such as: livestreaming (Sjoblom and Hamari, 2017), online social networking sites (Ku, Chen and Zhang, 2013; West and Turner, 2010; Whiting and Williams, 2013), and video sharing (Chiang and Hsiao, 2015). According to UGT, users seek out their media needs, instead of the media seeking out the user (Wang, Fink and Cai, 2008). UGT supports analysis of how users make choices for online streaming, and the roles users play in media engagement that can fulfill their psychological needs.

Guided by Uses and Gratification Theory (UGT), several motivations were identified for both streamers and viewers in online streaming (Hilvert-Bruce et al., 2018; Sjoblom and Hamri, 2017). UGT helps classify needs in five categories: Cognitive, Affective, Personal Integrative, Social Integrative, and Tension Release (Katz, Blumber, and Gurevitch, 1973; West and Turner, 2010), as presented in Table 1. Online streaming motivators related to the Cognitive need include Learning and information seeking for knowledge acquirement (van der Heijden, 2004; Papacharissi and Rubin, 2000; Sjoblom and Hamari, 2017). Motivators related to the Affective need are Entertainment and Adventure (Venkates, 2000; Sjoblom and Hamari, 2017). Motivators regarding the Personal Integrative need are Emotional connectedness, External support, Social support/recognition, and Social anxiety (Hernandez et al., 2011; Sjoblom and Hamari, 2017). Motivators for the Social Integrative need are Meeting new people, Social interactions, Sense of Community. Tension Release-related motivators are Escape, Relaxation and Distraction (Smock et al., 2011; Sjoblom and Hamari, 2017).

Learning and information seeking has been shown to be an important kind of Cognitive motivation for use in several online media contexts (Hamilton, Garretson and Kerne, 2014; Papacharissi and Mendelson, 2010; Whiting and Williams, 2013). Online video livestreaming enriches knowledge in an intuitive, fast, well-expressed way. It can enable streamers and viewers to interact in real time without any geographical restrictions. Eventually it enhances the effectiveness of the promotion of the broadcasted event. After a livestream is completed, users can continue to provide rebroadcasts and on-demand broadcasts at any time, effectively extending the time and location for livestreaming and maximizing the value of live broadcast content. For online streaming gaming, especially on the Twitch online streaming platform, users can better decide and find which game they want to play based on broadcasts they have watched in the past. Additionally, watching Twitch, users can learn about game strategies, tricks, tactics, and more (Sjoblom and Hamari, 2017).

As for Personal Integrative-related motivators, users can make up for the lack of community engagement in real life by participating in online communities (Miller, 2011). When online streaming users lack external support from family, friends, and local communities, they can seek out online communities with which they can share emotional connections and improve their psychological health by participating in such communities (Bargh and McKenna, 2004). According to reports, online social interaction and participation help reduce user loneliness 
(Valkenburg and Peter, 2009). This is especially important to people who find it difficult to communicate socially with others in real life; online communication can help such socially anxious people communicate well due to its abstracted nature (Baumeister and Leary, 1995; Desjarlais and Willoughby, 2010; Mazalin and Klein, 2008). The online streaming environment can provide alternatives to social activities in offline life, eliminating the obstacles that individuals with social anxiety may encounter in physical communities (Hilvert-Bruce et al., 2018).

Social Integration-related motivators (such as meeting new people, social interaction, and sense of community) are important because livestreaming platforms offer a virtual community center, where streamers and viewers can interact, communicate, and make new friends (Hamilton et al., 2014). In livestreaming environments, a sense of community is regarded as pursuing a sense of self-identity in the community (Hamilton, Garretson and Kerne, 2014); sense of community includes senses of community membership, social influence, and a sense of belonging to the livestreaming platform (McMillan and Chavis, 1986). In a livestream, users (including both streamers and viewers) can share the same sense of belonging and connection to each other based upon shared experiences, including: sharing the same dialect, similar social growth experiences and environment, and having the same or similar occupations. Streamers and viewers sometimes share life experience from their outside lives. The streamers might share many similar life and working experiences with viewers in real life. When streamers have similar experiences and/or similar identities in real life, they can more easily narrow the psychological distance between each other by participating in a community.

Tension Release and escape have an important impact on online streaming. Users can forget about their school, work, and other things when participating online. It can be a habit or a way to occupy their time. Watching online streams could also relax them and provide a pleasant form of rest (Sjoblom and Hamari, 2017).

Table 1: Typology of livestreaming motivators reported from literature

\begin{tabular}{|c|c|c|c|}
\hline Motivators & UG need type & Description & Literature \\
\hline $\begin{array}{l}\text { learning and } \\
\text { Information seeking }\end{array}$ & Cognitive & $\begin{array}{l}\text { Acquiring information, } \\
\text { knowledge, comprehension }\end{array}$ & $\begin{array}{l}\text { Papacharissi and Rubin, 2000; } \\
\text { Van der Heijden, 2004; Whiting } \\
\text { and Williams 2013; Hamilton, } \\
\text { Garretson and Kerne, 2014; } \\
\text { Hilvert-Bruce et al., } 2018\end{array}$ \\
\hline Entertainment & Affective & $\begin{array}{l}\text { Emotionally pleasant, or } \\
\text { aesthetic experience }\end{array}$ & $\begin{array}{l}\text { Venkatesh, 2000; Hanson and } \\
\text { Haridakis, 2008; Papacharissi } \\
\text { and Mendelson, 2010; Cheung } \\
\text { and Huang, 2011; Hamilton, } \\
\text { Garretson and Kerne, , 2014; } \\
\text { Friedländer, 2017; Hilvert- } \\
\text { Bruce et al., } 2018\end{array}$ \\
\hline Adventure & Affective & $\begin{array}{l}\text { Emotionally pleasant, or } \\
\text { aesthetic experience }\end{array}$ & $\begin{array}{l}\text { Venkatesh, 2000; Hanson and } \\
\text { Haridakis, 2008; Papacharissi } \\
\text { and Mendelson, 2010; Cheung } \\
\text { and Huang, 2011; Hamilton, } \\
\text { Garretson and Kerne, } 2014\end{array}$ \\
\hline Meeting new people & Social integration & $\begin{array}{l}\text { Enhancing connections with } \\
\text { family, friends }\end{array}$ & $\begin{array}{l}\text { Sherry et al., 2006; Chen and } \\
\text { Lin, 2011; Scholz, 2012; Pai and } \\
\text { Arnott, 2013; Whiting and } \\
\text { Williams, 2013; Hamilton, } \\
\text { Garretson and Kerne, 2014; } \\
\text { Friedländer, 2017; Hilvert- } \\
\text { Bruce et al., } 2018\end{array}$ \\
\hline Social interactions & Social Integration & $\begin{array}{l}\text { Enhancing connections with } \\
\text { family, friends }\end{array}$ & $\begin{array}{l}\text { Sherry et al., 2006; Chen and } \\
\text { Lin, 2011; Scholz, 2012; Pai and } \\
\text { Arnott, 2013; Whiting and } \\
\text { Williams, 2013; Hamilton, } \\
\text { Garretson and Kerne, 2014; } \\
\text { Friedländer, 2017; Hilvert- } \\
\text { Bruce et al., } 2018\end{array}$ \\
\hline Sense of Community & Social Integration & $\begin{array}{l}\text { Enhancing connections with } \\
\text { family, friends }\end{array}$ & $\begin{array}{l}\text { Sherry et al., 2006; Chen and } \\
\text { Lin, 2011; Scholz, 2012; Pai and } \\
\text { Arnott, 2013; Whiting and } \\
\text { Williams, 2013; Hamilton, }\end{array}$ \\
\hline
\end{tabular}




\begin{tabular}{|l|l|l|l|}
\hline Motivators & UG need type & Description & $\begin{array}{l}\text { Garretson and Kerne, 2014; } \\
\text { Friedländer, 2017; Hilvert- } \\
\text { Bruce et al., 2018 }\end{array}$ \\
\hline External support & Personal Integration & $\begin{array}{l}\text { Enhancing credibility, confidence, } \\
\text { and status }\end{array}$ & $\begin{array}{l}\text { Hernandez et al., 2011, Hilvert- } \\
\text { Bruce et al., 2018 }\end{array}$ \\
\hline Social support & Personal Integration & $\begin{array}{l}\text { Enhancing credibility, } \\
\text { confidence, and status }\end{array}$ & $\begin{array}{l}\text { Hernandez et al., 2011, Hilvert- } \\
\text { Bruce et al., 2018 }\end{array}$ \\
\hline Social anxiety & Personal Integration & $\begin{array}{l}\text { Enhancing credibility, confidence, } \\
\text { and status }\end{array}$ & $\begin{array}{l}\text { Hernandez et al., 2011, Hilvert- } \\
\text { Bruce et al., 2018 }\end{array}$ \\
\hline $\begin{array}{l}\text { Emotional } \\
\text { Connectedness }\end{array}$ & Personal Integration & $\begin{array}{l}\text { Enhancing credibility, } \\
\text { confidence, and status }\end{array}$ & $\begin{array}{l}\text { Hernandez et al., 2011, Hilvert- } \\
\text { Bruce et al., 2018 }\end{array}$ \\
\hline Escape & Tension release & Escape and diversion & $\begin{array}{l}\text { Lin, 2002; Hanson and } \\
\text { Haridakis, 2008; Courtois et al., } \\
\text { 2009; Papacharissi and } \\
\text { Mendelson, 2010; Whiting and } \\
\text { Williams, 2013 }\end{array}$ \\
\hline
\end{tabular}

Motivation can be also characterized as the degree to which persistent effort is focused toward a target (Johns, 1996), and the degree to which persistent effort a student pays toward learning can be perceived as motivation to learn (Law, Key and Yu, 2010). According to situational variables and environmental influences, motivation can be calculated internally by individuals and externally by sources (Amabile, Hill and Hennessy, 1994, Ryan and Deci, 2000, Law et al., 2010). Law, Kee and Yu (2010) indicated that motivation for computer programming in Elearning environment included intrinsic motivation (e.g., individual attitudes and goal), as well as extrinsic environment such as direction, reward, recognition, social pressure and competition.

Live coding is a regular pedagogical practice for teaching computer programming, where teachers write code without planning and project the learning process (Paxton, 2002). Live streaming is informal, which pursues learners' own learning without externally imposed requirements (Hall, 2009). Live streaming focused on entertainment content, such as sports (Hamari and Sjoblom, 2017). However, people also share knowledge through live streaming for interactive visual art (Fraser et al., 2019) and encourage engagement in language learning (Samat, Hashim and Yunus, 2019).

Coding education has been applied in live streaming environments and its implication in the context of computer science education has been discussed (Haaranen, 2018). Kubelka, Robbes and Bergel (2018) indicated that certain liveness features are beneficial to the way developers navigate source code and objects during the coding process. McDirmid (2016) gave out examples of how live coding environments acted as feedbacks or communication tools. In one way, programming training seems boring for some learners, but novice programmers and online learners/viewers have a strong interest in participating in live coding streaming. There is however a lack of a systematic view for motivations that enable users to receive educational and emotional benefits in coding learning. In addition, the analysis of detailed motivations also explains why people enjoy being live coding streamers and viewers, and possibly identify the challenges and prospects of using live streaming for online coding education.

\section{Method}

Literature analysis was conducted for identifying those reported motivations for livestreaming activities and a typology was developed for motivations for livestreaming coding learning, based on the literature guided by Use and Gratification Theory.

Content analysis (Bloom, 1956; Krippendorf, 2004) was conducted using the motivation categories found in the literature review: Cognitive, Affective, Social Integration, Personal Integration, and Tension Release. Live coding streams were accessed through using the https://www.twitch.tv/directory/, by choosing "Live Channel", and using any of "programming," "web development," and/or "software development" as the search tags. Live coding streams were evaluated by two researchers. A total of 256 streams in a time span of one week, from February 24 to March 2, 2019, were observed. Shortly after watching the stream, the two researchers compared and discussed the streamers' motivation categories, and one or more motivation categories were assigned if applicable. The coder pairs arrived at consensus on the categorization, therefore, an inter-coder reliability of $100 \%$ can be reached. 
User feedback/threads and blog posts regarding a live coding platform, LiveEdu.tv (https://blog.educationecosystem.com/?s=live+streaming), were reviewed and evaluated as selective supporting cases for finding motivation. The blog posts site contained diverse discussion topics posted by the streamers; only those related to perception of motivation for livestreaming were harvested. In total, twenty six discussion posts were harvested and categorized. These data points provide empirical support for the motivation analysis performed by the researchers.

\section{Result and Discussion}

Livestreaming could offer numerous benefits for those seeking to learn computer coding. Livestreaming for computational programming allows viewers to participate in the programming process; for example, viewers can participate by performing code reviews, suggesting alternative methods, and discovering errors that the streamer may have missed (Haaranen, 2017). There are multiple livestreaming sites for computer coding practice and learning such as Twitch programing and liveEdu.tv.

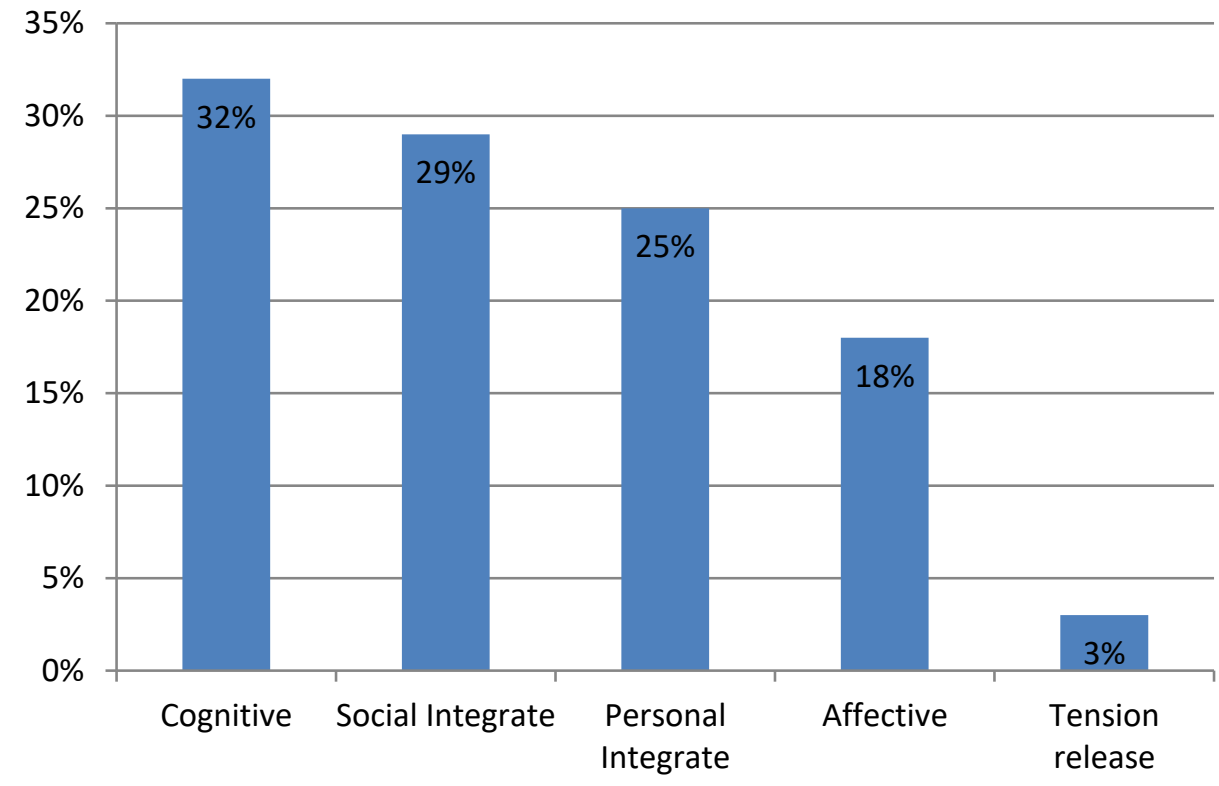

Figure 1: Distribution of motivation categories; sometimes multiple assignments, $\mathrm{N}=256$

Content analysis from 256 live coding streams from Twitch.tv (Figure 1), indicated that the ranking of motivation categories in decreasing order is: Cognitive, Social Integration, Personal Integration, Affective, and Tension Release. Live coding streams were primarily motivated by the purpose of learning and information seeking, followed by meeting new people and community outreach, as well as gaining social and community support. In comparison to other types of livestreaming, such as gaming and sports (Zimmer, 2018), it showed less motivation for entertainment purpose.

Livestreaming with computer programming might be boring to some, only showing a bunch of computer code on the screen. There is no speaking, no joking and singing like other popular event livestreaming. However, it attracts a great number of people to watch and participate for learning and fun. This indicates that live coding demonstrations provide unique motivations for both streamers and viewers.

In a typical live coding experience, the programmer does not speak a word; sometimes they put on some soft music. The programmer can quietly broadcast their live coding practice for several hours without any interaction with the audiences. Every line of code's inputs, along with the programmer's logical flow of coding (including switching, splitting, deletion, addition, modification, etc), are projected on-the-fly on the screen. In general, there is also a webcam in the lower corner showing the programmer's face (Figure 2). 


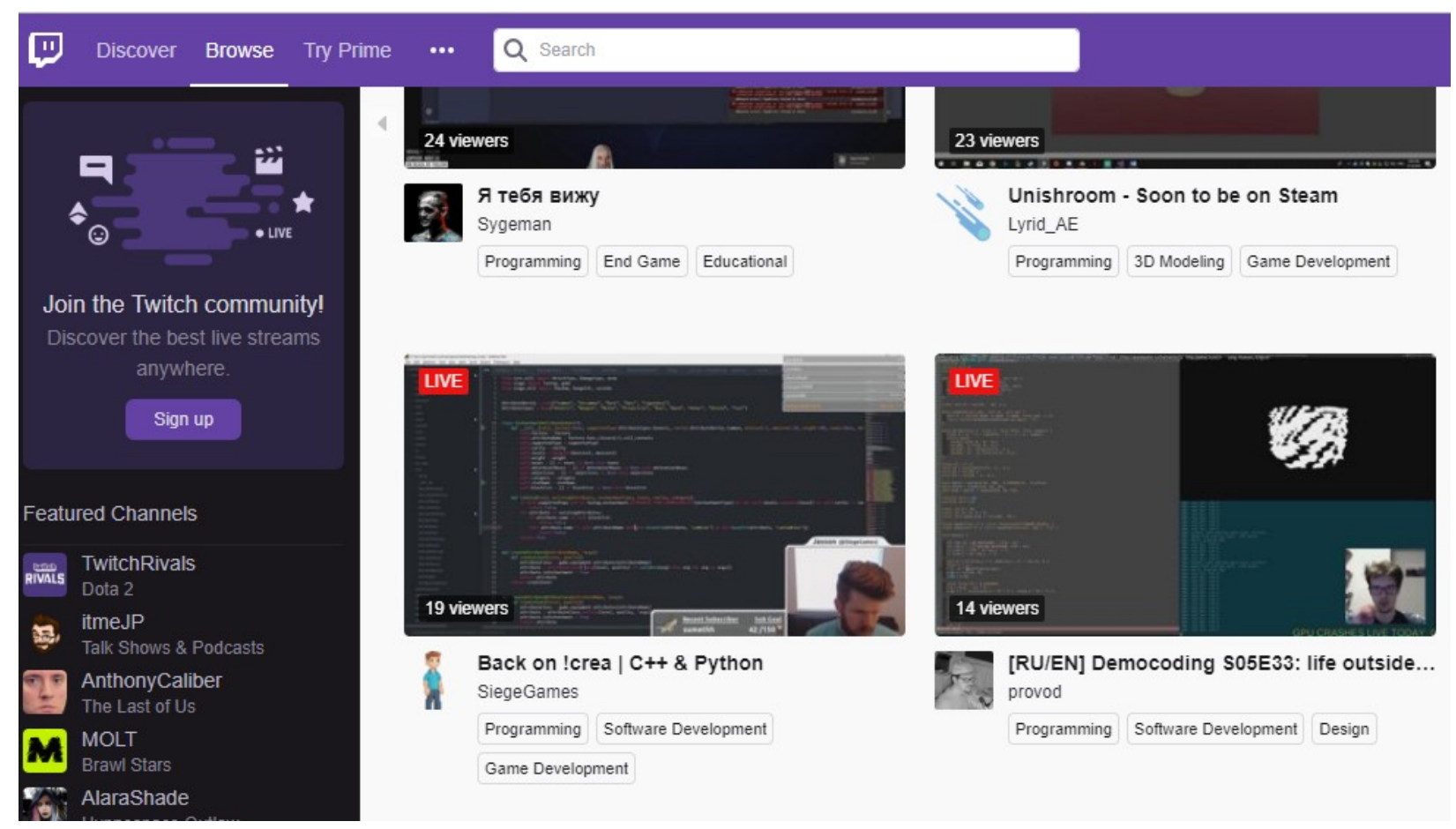

Figure 2: A screenshot of live coding streaming from Twitch.tv

\subsection{Cognitive decomposition and thinking aloud}

In 1956, Bloom presented his take on cognitive levels. From lowest to highest, they are as follows: recall, comprehension, application, analysis, and synthesis and evaluation (Bloom, 1956). Programmers need to: recognize coding structures, understand programming rules, apply programming tasks, and have debugging skills, as well as advanced programming skills and evaluation capability (Shneiderman and Mayer, 1979; Robins, Rountree and Rountree, 2003). Programming practice is a kind of higher-order learning activity, which requires the full imagination for dynamic features of the program and their all possible execution paths. New programmers usually lack the imagination necessary for expressing their programming ideas into an executable solution, as this develops over time. Live coding displays a complete and unedited view of how experienced programmers apply programming key concepts to produce a fine-tuned program construction process.

Live coding streaming accurately mimics a real coding environment and practice and provides the performance of programming to a live audience. When carrying out a coding project development, firstly, it is important to clearly specify the user requirements in detail; this can be accomplished by defining related data concepts and entities in a clear and unambiguous manner. Next is to begin constructing a general solution. If the problem is relatively large and complex, it may be necessary to decompose the problem into smaller tasks until is small enough to be solved with one or two data structures and algorithms. Live coding allows users to observe such decomposition process in detail and step by step.

"It's refreshing and challenging to try to understand how someone else is thinking in code. I'm thinking that at least if whoever is coding is thinking out loud it light be easier."

Developing proficient skills in computational thinking involves building a variety of problem-solving skills that requires much in the way of coding practice. Live coding facilitates observing the development process, including the pitfalls of programming language design. However, the quality of learning depends on the person who is writing the code. For example, how to abstract a specific solving program into a data structure and the chosen algorithm, or whether they clearly spell out the logic and methods behind the solutions that they demonstrate in real time.

"Thought process, I consider myself a relatively proficient developer, but I often struggle with the overall scheme of a program. As in, I know I need $X, Y$, and $Z$, but not necessarily the best place to put $X, Y$, and Z." 
"I've been trying to learn on and off for years now - I know the very basics but putting it all together still eludes me."

The coding process involves taking a big project and breaking it down into smaller, more manageable tasks. This is typically not a one-time deal and it involves continuous refinement. Live-coding can reflect such a process in real time. Finally, it implements specific algorithms to solve a small problem. If the problem is relatively small and simple, it can be easily accomplished. If it is more difficult to tackle, a streamer may look for literature and sources that report a solution. Live coding enables the viewer to observe a refinement process in an easily understood format. A blog discussion reflects a similar idea:

"The streams are not totally polished and bugless (they reflect actual development process but they are educational.)"

\subsection{Good habit coding}

In traditional programming education, a large amount of autodidactic behavior is required. Live coding can help educate users on how to translate the design of the code into an actual, functioning portion of the code. One solution might involve several designs, and the algorithm requires comparison in coding design for scalability, maintenance, and modularity. Other aspects, such as an algorithm's time and spatial complexity, also need to be given special attention. Blog discussion threads have this to say on the subject:

"How experienced programmers achieve good architecture. Specifically, decoupling/modularization, and the rationale behind their decisions."

"I'm interested in the process people use. I have a colleague who says vim is bad for rails development but I see vim being used all the time in screen casts. It's all down to personal preference but it's still interesting."

"Want to see what best practices, technologies people are using. Want to get better."

Live coding has some advantages in terms of developing debugging skills in programmers, as well as helping them form good habits in terms of appropriate programming language use. Streamers can share their daily experiences of good coding practice live, thus granting their audience a good look at the streamer's workflow. As an example of good programming habits one can consider $\mathrm{C}++$ : the $\mathrm{C}++$ programing language (cpp) has some common ways to reduce procedures like "if null == x"; this kind of good-habit code writing can avoid accidentally assigning values in conditional statements, thus granting better program flow. Several blog post threads also comment on this facet of live programming, as can be seen below:

"Real projects, live code are boring, slow pace, lot of debugging, lot of thinking and that was the real spirit."

"I want to see what people do to write more efficiently."

\subsection{Information seeking and resources sharing}

Live coding, as has been discussed previously in this paper, can benefit users in a multitude of ways; however, the aforementioned reasons are far from the only positive factors to be found in live coding. Another upside to live coding is in how it demonstrates methods for retrieving multiple computational programming resources and synthesizing them together. If a solution to a coding problem exists, then generally speaking there is a corresponding open source library artifact providing an API or an existing algorithm. The problem with the algorithms is finding results that can be referenced in a corresponding field. If a user finds an existing result, there is usually an open source library. Calling an API is a call to an existing algorithm. Online streaming can easily demonstrate such a process by finding the appropriate coding resources and putting them together on the screen. Some blog discussion threads comment on this aspect of live coding:

"I like to see the tools they are using and how they use them."

"I'm self-taught and it's really hard to find resources directed at the intermediate level programmer." "Yeah this is what I think... It could provide a decent resource for people who're out the 'what's a loop' stages... It's a shame people don't seem to be using 'github' in conjunction with the vids, that'd help the documentation a lot" 
"Mainly workflow, tools, and dependencies/libraries they are using. There is always someone out there that knows some hidden gem that can make my life much easier."

\subsection{Mutual, impromptu, participative environment}

Live coding provides a casual environment for coding practitioners and learners as well as encouragement for mutual learning; in this setting, streamers and viewers can share their computational thinking experience live with each other in a casual way. A blog discussion thread shows this mode of thought to be present in streaming communities:

"It attracts a lot of programmers to participate. Other programmers found the live streaming is overcoming the coding programs, but also their own coding challenges or difficulties they experienced. Programmers get together and formed a mutual live learning environment."

Livestreaming means no preparation, no plan to follow, no polishing content or editing videos. It has the advantage of allowing users to observe and learn the whole computational thinking process in the real life environment. Blog discussion posts provide support for the above idea:

"The main idea was for us streamers to just get the stream started, work on whatever we wanted, no plan to follow, no polished or edited video. Things were not even tutorial, they were just real life coding."

"Live coding wasn't about educating, it was about sharing ideas and the projects people are working on. That's very different from an educational platform. With live coding people did learn, but the streamers weren't educators. For that they would need some sort of curriculum/plan to follow, and... that is exactly what you're encouraging."

"Just for fun. A more passive pair-programming experience."

\subsection{Entertainment}

Livestreaming videos offer real and rich content. Computer programming is complex and sophisticated, and as such can be boring. Going to a concert to listen to a live concert is more popular than simply listening to a record. A talk show is more interesting than reading a manuscript seriously. This is because the former is more interactive, authentic, and unpredictable. Everyday news also needs to be watched at a fixed moment, but a live webcast is different. It changes the delay of previous news broadcasts, allows viewers to directly see the actual situation on the scene, and it is a scene without post-processing clips. Compared to reproducible media (such as text), audio-visual media have a far greater abundance of features; an example of such features is the ability to record things, including speech rate, emotions, and gestures, which are all engaging features for audiences. Live coding offers a great deal of entertainment for users, especially compared to other methods of increasing coding experience. Once more, this is supported by discussion posts from live coding communities themselves:

"Learning to code can be quite dull,"... "There's not much of a social element. We thought this could be a way for people to learn and also be entertained." "Social elements such as livestreaming can be used to share momentful and live experiences to others that share the same interest."

"What I got out of this site was contact with other streamers, programmers and entertainment, I liked the social aspect of checking in on what others were working on. It's easy to see that most live coding style content has a limited shelf-span, typically it's only worth watching live, and you need videos that can be found easily and revisited by old and new users over and over again."

\subsection{Emotional connectedness}

Even beyond the underlying logic of mutual learning, there is a far greater demand: in traditional systems of programming, the programmer may feel extreme social isolation; however, if there is a live platform, coders can feel a sense of connection to their audience. They have companions, individuals who are there with them, even if they are hundreds of miles away. If the programmer experiences difficulties, they have a community, people with whom they can work together: problems can be discussed together, and participants can use their talents and experiences for certain unique expertise. Live coding platforms serve as a community center, which can be very valuable to these programmers. Live coding broadcasting touches on a very important psychological phenomenon, a mental state referred to as the feeling of being on the spot; this is where the streamer is, even if they are alone at home, able to feel as though they are in the company of many others, namely, their audience. 
A streamer and their viewers can discuss things together, creating a sense of presence that can't be underestimated, brought about by social participation.

"As someone who is a hobbyist looking to make it a full time career it's really nice to see how people approach different problems. I like to glean as much information as I can about their workflow and what kinds of tools they use daily in order to be productive."

"I observe other coders while wearing a white lab coat and carrying a clipboard. I can inspect the way other specimens program and hopefully assimilate other techniques."

\subsection{Reward and appreciation}

Live coding allows streamers to easily share their coding ideas and solutions to a live audience. They want their streaming to be valuable. They love to see others take their solutions or comments into account and see their solutions beneficial others, something which improves their reputation and credibility in the community.

"Some streamers might like this but it is not something of value for viewers. If no viewers watch the content being streamed it is of no value..."

"Now you want... those 'monetizable' tutorials. A tutorial is straight to the point, bugless, perfectly coded, well edited, no silent thinking moments...."

\subsection{Adventure and curiosity}

Maslow (1971) believed that humans have the need to actively explore their environment. They are full of curiosity about everything they can observe, and are fascinated by mysterious, unknown, and unpredictable things. Humans are also irrevocably interested in other human beings; seeing how individuals act and interact with one another is a prime source of intrigue for our species. Livestreams are a source of such interaction which happens in real time, the stream offering a view of the personality of the streamer; this can act as a way of satisfying the viewer's interpersonal curiosity. One blog discussion thread states the following:

"I am more curious onto what people are designing."

\subsection{Escape and tension release}

Learning to code is a stressful process; it requires high levels of focus and attention for computational thinking. Live coding platforms enable a casual environment for learning to code that allows viewers to relax and lay back away from their boring and stressful working environment to have some fun. Blog discussions state the following corresponding points:

"Learning different languages through osmosis because I'm too lazy to study"

"Plus it's kind of zen for me. It's really relaxing to watch."

\section{Motivation Model}

Content analysis from twenty-six "LiveEdu.tv" forum posts identified motivational needs for live coding from both streamers and viewers. These empirical data combined with the analysis of "Twitch.tv" live streaming data, support the creation of a motivation model based on UGT. It found that motivation focuses heavily on cognitive needs, including information search, cognitive decomposition, thinking aloud, good habit coding, and resource sharing (Figure 3). In such a collaborative learning environment, streamers and viewers achieve mutual advantages and seek personal rewards and emotional relationships. The need for entertainment and curiosity is certainly not insignificant. Both streamers and viewers avoid a stressful coding environment and are more relaxed during the coding process. 


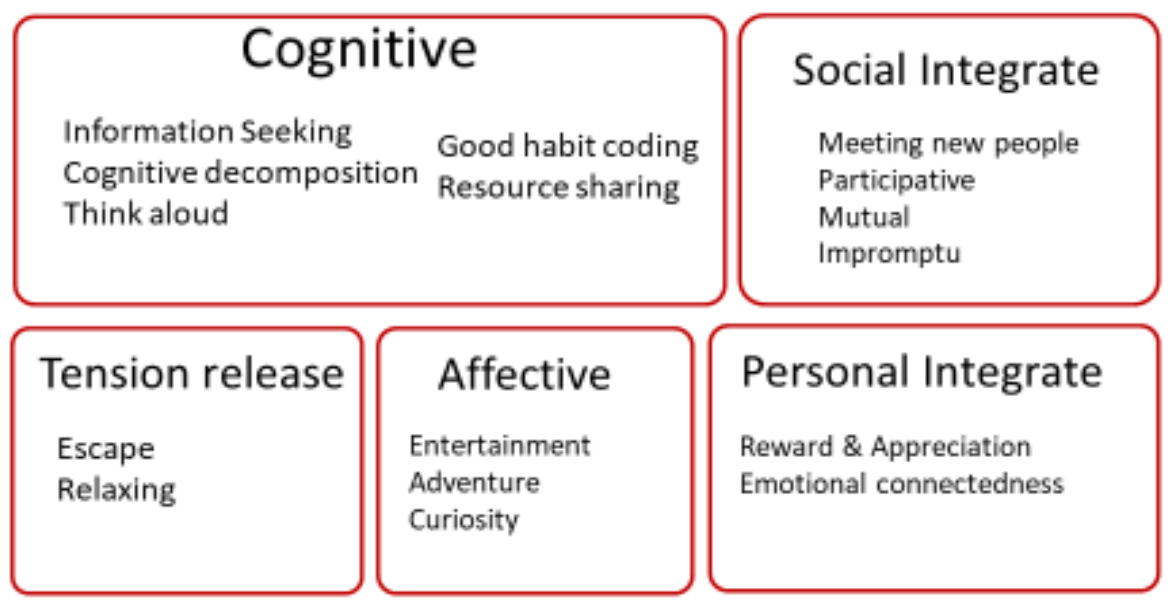

Figure 3. Motivation model in live coding streaming based on UGT

\section{Limitations}

This study is a preliminary study based on UGT theory as a framework, and the analysis is with a limited sample size. Additional observations can be explored with different coders for further repeated analysis. New surveys and interviews could also be conducted with both viewers and programmers for further exploring their live coding motivations and behind.

Live coding offers new opportunities for the coding education of novice learners. However, evaluating the quality of live coding streams is difficult. Those who determine the quality of a stream cannot just rely on people who watch the stream, as it is felt that viewers of streams are not an accurate enough assessment; after all, the levels of coding capability in viewers varies from person to person. A set of specifications is required to ensure quality and to develop a set of appropriate standards to evaluate the coding quality during the livestream.

If live coding is applied for computational thinking education, there should be specified guidelines for streamers who write code; for example, the concrete computational thinking should be spelled out for solutions to specific problems. Also it is important to ensure that the previous, imperfect work-arounds that had been tried are shared, as well as mistakes that had been experienced during the solving of similar problems.

"Value is hard to define..."

"They don't understand that it's not necessary to mute/remove the stream. It's a mistake to want 'better quality'."

"Silent random uneducational streaming is of no value for viewers."

The study provided a snapshot of using an emerging online livestreaming program for programming education. As more learners choose online livestreaming for programming education, it is imperative to understand how and why they are motivated to learn through such opportunities. Understanding motivation allows to create more personalized and interactive live streaming tools. The exploration and collection of streaming content can be supported by new adaptive learning modules to enable cognitive decomposition on the fly. Similarly, stressreduced learning features with incentives and rewards help to create an efficient and equitable learning environment for programming learning.

\section{Conclusion}

From previous methods of information sharing (such as text, voice, and pictures) to today's innovative livestreaming, information sharing techniques have evolved and been enhanced greatly over the years, changing in terms of quantity, efficiency, and expressive potential. Livestreaming offers a more interactive and presencebased method of communication and maximizes the possibility of maintaining social relationships. Livestream broadcasting content can vary greatly, from original shows to today's diverse live events, including the following: outdoor live activities, news live reports, eating, exploring; education; daily life; and more. Livestreaming can be seen as having significantly impacted many people's daily lives. 
Traditional TV or other video media only attracts people through having extremely high-quality content due to its lack of communication. People will recommend content to their friends after they have watched it if they found it to be very good. Unlike watching a movie, however, once people think that an online streamer is even slightly interesting, they may tell others through methods such as online social media platforms; this causes more people to hear about such streams, as they spread much faster than other comparable media sources, and can easily gather crowds of people to join the livestream community.

Since livestreaming can easily reach a large audience, understanding the underlying psychological needs of a live streamer (and their motivation for livestreaming) could shine a light on the audience's motivation. This study took the method of empirical research through content analysis of online livestreaming blog discussions, analyzed the psychological intentions of live coding audiences and streamers, developed a motivation model, and came to the conclusion that the users of live coding mainly focus on the following types of motivation: learning and information seeking, entertainment and adventure, meeting new people and gaining a sense of community, seeking external recognition and support, and seeking escape and relaxation. This indicates that livestreaming can be facilitated as personal learning experience sharing tools for computational thinking training and coding practice demonstration. The findings and motivation model help develop innovative motivationspecific learning tools that support interactive, adaptive, personal, and experience-based computer programming practices and training.

\section{Acknowledges}

The authors want to thank the two anonymous reviewers for their insightful comments.

\section{Reference}

Abdous, M. H., and Yen, C. J., 2010. A predictive study of learner satisfaction and outcomes in face-to-face, satellite broadcast, and live video-streaming learning environments. The Internet and Higher Education, 13(4), pp. 248-257.

Amabile, T. M., Hill, K. G., Hennessey, B. A. and Tighe, E. M., 1994. The Work Preference Inventory: assessing intrinsic and extrinsic motivational orientations. Journal of Personality and Social Psychology, 66(5), pp. 950.

Bloom, B. S., 1956. Taxonomy of educational objectives. Vol. 1: Cognitive domain. New York: McKay, pp. 20-24.

Blumler, J.G. and Katz, E., 2014. The uses of mass communications: current perspectives on gratifications research. Beverly Hills, CA: Sage.

Chen, C. C. and Lin, Y. C., 2018. What drives live-stream usage intention? The perspectives of flow, entertainment, social interaction, and endorsement. Telematics and Informatics, 35(1), pp. 293-303.

Cheung, G. and Huang, J., 2011. Starcraft from the stands: understanding the game spectator. In: Proceedings of the SIGCHI Conference on Human Factors in Computing Systems, CHI 2011, Vancouver, BC, Canada, May 7-12, 2011(pp. 763 772). DOI:10.1145/1978942.1979053

Chiang, H., and Hsiao, K., 2015. YouTube stickiness: the needs, personal, and environmental perspective. Internet Research, 25(1), pp. 85-106.

Chorianopoulos, K. and Lekakos, G., 2007. Learn and play with interactive TV. Computers in Entertainment (CIE), 5(2), p.4.

Courtois, C., Mechant, P., De Marez, L. and Verleye, G., 2009. Gratifications and seeding behavior of online adolescents. Journal of Computer-Mediated Communication, 15(1), pp. 109-137.

Derry, S. J., Pea, R. D., Barron, B., Engle, R. A., Erickson, F., Goldman, R., Hall, R., Koschmann, T., Lemky, J.L., Gamoram Sherin, M and Sherin, B. L., 2010. Conducting video research in the learning sciences: Guidance on selection, analysis, technology, and ethics. The Journal of the Learning Sciences, 19(1), pp. 3-53.

Emarketer, 2017. How are internet users watching live streaming? Facebook viewership grew slightly, while other platforms slipped. Available at: https://www.emarketer.com/Article/How-Internet-Users-Watching-LiveStreaming/1015036. [Accessed 27 June 2021]

Fingas J., 2018,. Nearly two billion people have watched Facebook Live broadcasts. April $6^{\text {th }} 2018$. Available at:https://www.engadget.com/2018/04/06/facebook-live-2-year-statistics/ [Accessed 20 March 2019]

Fraser, C. A., Kim, J. O., Thornsberry, A., Klemmer, S. and Dontcheva, M., 2019. Sharing the studio: How creative livestreaming can inspire, educate, and engage. In: Proceedings of the ACM Conference on Creativity and Cognition (C\&C) 2019 San Diego, CA. (pp. 144-155). New York: ACM. DOI: https://doi.org/10.1145/3325480.3325485

Friedländer, M.B., 2017. Streamer motives and user-generated content on social live-streaming services. Journal of Information Science Theory \& Practice, 5(1), pp. 65-84.

Haaranen, L., 2017. Programming as a performance: live-streaming and its implications for computer science education. In: Proceedings of the 2017 ACM Conference on Innovation and Technology in Computer Science Education. Bologna, Italy June 2017 (pp. 353-358). New York: ACM, DOI:https://doi.org/10.1145/3059009.3059035

Hall, R., 2009. Towards a fusion of formal and informal learning environments: The impact of the read/write web. Electronic Journal of E-learning, 7(1), pp. 29-40.

Hamari, J., and Sjöblom, M., 2017. What is eSports and why do people watch it?. Internet Research, 27, 2, pp. 211-232. 
Hamilton, W. A., Garretson, O. and Kerne, A., 2014. Streaming on twitch: fostering participatory communities of play within live mixed media. In Proceedings of the 32nd annual ACM conference on Human factors in computing systems, Toronto, OH, Canada, April 2014 (pp. 1315-1324). New York: ACM,

Hanson, G. and Haridakis, P., 2008. YouTube users watching and sharing the news: A uses and gratifications approach. Journal of Electronic Publishing, 11(3). DOI: https://doi.org/10.3998/3336451.0011.305

Hernandez, D., 2016. Game creator success on Twitch: Hard numbers. Available at: https://blog.twitch.tv/en/2016/07/13/game-creator-success-on-twitch-hard-numbers-688154815817 [Accessed 20 March 2019]

Hernandez, B., Montaner, T., Sese, F. J., and Urquizu, P., 2011. The role of social motivations in e-learning: How do they affect usage and success of ICT interactive tools?. Computers in Human Behavior, 27(6), 2224-2232.

Hilvert-Bruce, Z., Neill, J. T., Sjöblom, M. and Hamari, J., 2018. Social motivations of live-streaming viewer engagement on Twitch. Computers in Human Behavior, 84, pp. 58-67.

Kats, R., 2017. For some, live streaming video is already a constant. Available at: https://www.emarketer.com/Article/Some-Live-Streaming-Video-Already-Constant/1016137 [Accessed 20 March 2019]

Katz, E., Blumler, J. G., and Gurevitch, M., 1973. Uses and gratifications research. The Public Opinion Quarterly, 37(4), 509523.

Krippendorff, K., 2004. Content analysis: An introduction to its methodology (2nd ed.). Thousand Oaks, CA: Sage.

Kubelka, J., Robbes, R. and Bergel, A., 2018. The road to live programming: insights from the practice. In: Proceedings of the 40th International Conference on Software Engineering Gothenburg, Sweden, May 2018 (pp. 1090-1101). New York: ACM,.

Law, K. M., Lee, V. C. and Yu, Y. T., 2010. Learning motivation in e-learning facilitated computer programming courses. Computers \& Education, 55(1), pp. 218-228.

Lin, C. A., 2002. Perceived gratifications of online media service use among potential users. Telematics and Informatics, 19(1), pp. 3-19.

Maslow, A., 1971. The farther reaches of human nature. New York: The Viking Press.

McDirmid, S., 2016. The promise of live programming. In: Proceedings of the 2nd International Workshop on Live Programming, LIVE, Rome, Italy (Vol. 16),

McQuail, D., 1993. Mass communication theory. Sage: London.

Mone G., 2015. Next in live entertainment: watching people code.Communications of the ACM, March 24, 2015Available at: https://cacm.acm.org/news/184758-next-in-live-entertainment-watching-people-code/fulltext [Accessed 20 March 2019]

Pai, P. and Arnott, D. C., 2013. User adoption of social networking sites: Eliciting uses and gratifications through a meansend approach. Computers in Human Behavior, 29(3), pp. 1039-1053.

Papacharissi, Z. and Mendelson, A., 2010. 12 Toward a new (er) sociability: uses, gratifications and social capital on Facebook. Media Perspectives for the 21st Century, pp. 212-230. DOI:10.4324/9780203834077

Papacharissi, Z., and Rubin, A. M., 2000. Predictors of internet use. Journal of Broadcasting \& Electronic Media, 44(2), pp. 175-196.

Patel N., 2018. Why you should care about live streaming in 2018. Available at: https://neilpatel.com/blog/livestreaming-importance-2018/ [Accessed 20 March 2019]

Paxton, J., 2002. Live programming as a lecture technique. Journal of Computing Sciences in Colleges, 18(2), pp. 51-56.

Repenning, A., Webb, D. and loannidou, A,. 2010. Scalable game design and the development of a checklist for getting computational thinking into public schools. In: Proceedings of the 41st ACM technical symposium on computer science education Milwaukee, Wisconsin, USA, March 10-13, 2010 (pp. 265-269). New York: ACM,

Robins, A., Rountree, J. and Rountree, N., 2003. Learning and teaching programming: A review and discussion. Computer Science Education, 13(2), pp. 137-172.

Rubin, A. M., 2009. Uses and gratifications. In: R. L. Nabi and M. B Oliver (eds). The SAGE handbook of media processes and effects. California, CA: Sage Publications.

Ryan, R. M. and Deci, E. L., 2000. Self-determination theory and the facilitation of intrinsic motivation, social development, and well-being. American Psychologist, 55(1), pp. 68.

Samat, N. A. A., Hashim, H., and Yunus, M. M., 2019. Live streaming: a new platform for ESL learning. Creative Education, 10(12), pp. 2899-2906.

Scholz, T. M.. 2012. New broadcasting ways in IPTV-The case of the Starcraft broadcasting scene. In World Media Economics \& Management Conference, Thessaloniki, Greece, 23-27 May 2012.

Sherry, J. L., Lucas, K., Greenberg, B. S. and Lachlan, K., 2006. Video game uses and gratifications as predictors of use and game preference. In: P. Vorderer and J. Bryant (eds). Playing video games: motives responses, and consequences (pp.213-224). Mahwah, NJ: Lawrence Erlbaum Associates.

Shneiderman, B. and Mayer, R., 1979. Syntactic/semantic interactions in programmer behavior: A model and experimental results. International Journal of Computer \& Information Sciences, 8(3), pp. 219-238.

Sjöblom, M. and Hamari, J., 2017. Why do people watch others play video games? An empirical study on the motivations of Twitch users. Computers in Human Behavior, 75, pp. 985-996.

Smith, T., Obrist, M. and Wright, P., 2013. Live-streaming changes the (video) game. In: Proceedings of the 11th European Conference on Interactive TV and Video (pp. 131-138). New York: ACM. DOI:10.1145/2465958.2465971 
Smock, A. D., Ellison, N. B., Lampe, C., and Wohn, D. Y., 2011. Facebook as a toolkit: A uses and gratification approach to unbundling feature use. Computers in Human Behavior, 27(6), 2322-2329.

Van der Heijden, H., 2004) User acceptance of hedonic information systems. MIS quarterly, 28(4), pp. 695-704.

Venkatesh, V., 2000. Determinants of perceived ease of use: Integrating control, intrinsic motivation, and emotion into the technology acceptance model. Information Systems Research, 11(4), pp. 342-365.

Whiting, A. \&and Williams, D., 2013. Why people use social media: a uses and gratifications approach. Qualitative Market Research: An International Journal, 16(4), pp. 362-369.

Zimmer, F., 2018. A content analysis of social live streaming services. In: Meiselwitz G. (eds) International Conference on Social Computing and Social Media: User experience and behavior, SCSM 2018. Lecture Notes in Computer Science, vol 10913. (pp. 400-414). Cham: Springer. DOI:10.1007/978-3-319-91521-0 29 